\title{
DISCLOSURE EM CLUBES DE FUTEBOL: ESTUDO SOBRE OS REFLEXOS DA LEI DO PROFUT ${ }^{1}$
}

\author{
DISCLOSURE IN SOCCER CLUBS: STUDY ON THE REFLEXES \\ OF THE PROFUT LAW
}

Wagner Lemos Umbelino ${ }^{2}$

Graduação pela Universidade Federal do Ceará - UFC

Universidade Federal do Ceará - UFC

wagnerlemos18@hotmail.com

https://orcid.org/0000-0002-0700-558X

Vera Maria Rodrigues Ponte

Doutorado pela Universidade de São Paulo - USP

Universidade Federal do Ceará - UFC

vponte@fortalnet.com.br

https://orcid.org/0000-0003-4910-9720

Régis Barroso Silva

Mestrado pela Universidade Federal do Ceará - UFC

Centro Universitário Christus - Unichristus

regis.silva@alu.ufc.br

https://orcid.org/0000-0002-3749-6199

Maiara Chagas Lima

Graduação pela Universidade Federal do Ceará - UFC

Universidade Federal do Ceará - UFC

maiaralimma@gmail.com

https://orcid.org/0000-0002-0695-664X

\section{RESUMO}

Objetivo: Investigar o nível de disclosure decorrente da adesão ao PROFUT, pelos clubes de futebol brasileiros, e sua relação com o desempenho econômico-financeiro e esportivo no decorrer dos anos de 2015 e 2016.

Fundamento: No Brasil, as administrações de alguns clubes de futebol vêm refletindo uma situação de dificuldade financeira. O governo propiciou, através da Lei do PROFUT, a possibilidade de refinanciamento de dívidas fiscais para essas entidades, exigindo como contrapartida a adoção de práticas de responsabilidade fiscal, financeira e de gestão, refletindo diretamente na divulgação contábil.

\footnotetext{
${ }^{1}$ Artigo recebido em: 30/01/2018. Revisado por pares em: 12/06/2018. Reformulado em: 15/06/2018. Recomendado para publicação, após a segunda rodada, em: 02/07/2018 por Dimas Barreto de Queiroz (Editor Adjunto). Publicado em: 26/12/2018. Organização responsável pelo periódico: UFPB

${ }^{2}$ Endereço: Avenida da Universidade, n. 2431, Benfica - Fortaleza/Ceará, 60020-180
} 
Método: Foram investigadas mudanças no nível de disclosure entre os anos levantados através de teste de diferença entre médias e, adicionalmente, a existência de associação entre os indicadores de desempenho econômico-financeiro e esportivo através de testes de Correlação de Pearson e Análise de Correspondência Múltipla.

Resultados: A adesão ao PROFUT não provocou melhoras de divulgação nos anos estudados. Foi identificada proximidade entre o tamanho dos clubes e o nível de disclosure e inexistência de relação entre os desempenhos econômico-financeiro e esportivo. Percebeu-se que os clubes de futebol não retornaram com contrapartidas equivalentes aos benefícios proporcionados pelo PROFUT, uma vez que não foram apresentados indícios de melhorias no desempenho econômico-financeiro, tampouco no desempenho esportivo.

Contribuições: Discute-se o nível de aderência ao disclosure requerido pelo PROFUT e a sua relação com a divulgação dos times de futebol e os desempenhos econômico-financeiro e esportivo. Suscita questionamentos quanto à postura das entidades avaliadas, no que se refere às contrapartidas informacionais oferecidas à sociedade, além de demonstrar que, nessas entidades, o disclosure está relacionado com níveis maiores de desempenho econômico-financeiro.

Palavras-chave: Divulgação. Desempenho esportivo. Desempenho econômico-financeiro. Clubes de futebol.

\section{ABSTRACT}

Objective: To investigate the level of disclosure due to the adhesion to PROFUT, by Brazilian football clubs, and their relation with the economic-financial and sports performance during the years of 2015 and 2016.

Background: In Brazil, the administrations of some football clubs have been reflecting a situation of financial difficulty. Through the PROFUT Law, the government provided the possibility of refinancing tax debts for these entities, requiring, as a counterpart, the adoption of fiscal, financial and management responsibility practices, directly reflected in the accounting disclosure.

Method: The adhesion to the PROFUT did not cause improvements in the years studied. It was identified proximity between the size of the clubs and the level of disclosure and inexistence of relationship between economic-financial and sports performance. It was noticed that football clubs did not return with counterparts equivalent to the benefits provided by PROFUT, since there were no indications of improvements in economic-financial performance nor in sports performance.

Results: The adhesion to the PROFUT did not cause improvements in the years studied. It was identified proximity between the size of the clubs and the level of disclosure and inexistence of relationship between economic-financial and sports performance. It was noticed that football clubs did not return with counterparts equivalent to the benefits provided by PROFUT, since there were no indications of improvements in economic-financial performance nor in sports performance.

Contributions: It discusses the level of adherence to the disclosure required by PROFUT and its relationship with the disclosure of football teams and the economic-financial and sports performance. It raises questions about the position of the entities evaluated, regarding the informational counterparts offered to the company, and also demonstrates that, in these entities, disclosure is related to higher levels of economic and financial performance.

Keywords: Disclosure. Sports performance. Economic-financial performance. Football clubs. 


\section{INTRODUÇÃO}

Apesar do período de instabilidade econômica pelo qual a economia tem passado, os clubes brasileiros de marcas mais valiosas geraram uma receita total de $\mathrm{R} \$ 4,96$ bilhões no ano de 2016, segundo pesquisa da BDO RCS Auditores Independentes (2017), um aumento de 29\% se comparado com o faturamento de 2015. Dessa forma, nota-se que o futebol não deve ser objeto de interesse apenas de torcedores e imprensa especializada, pelo contrário, deve ser observado como parte importante da atividade econômica do país.

Sendo o futebol relevante para a economia nacional, o governo necessita estabelecer parâmetros para o funcionamento dos clubes enquanto entidades, incentivando o seu desenvolvimento e proporcionando condições para que a sociedade possa acompanhar o seu desempenho, ou seja, exigindo a divulgação de informações contábil-financeiras.

Com o objetivo de incentivar o desenvolvimento de um setor ou mesmo contribuir para a implantação de empresas em espaços específicos, o governo pode conceder benefícios, os quais podem ser conceituados como subvenções ou como assistências governamentais.

Segundo o CPC 07 a assistência governamental é uma ação do governo com a finalidade de fornecer benefícios econômicos específicos à uma entidade ou a um grupo de entidades que atendam critérios predeterminados. Rodrigues, Silva e Faustino (2011) e Taveira (2009) esclarecem que esses tipos de benefícios podem se materializar de diversas formas, como isenções e/ou reduções tributárias, empréstimos subsidiados, parcelamentos, incentivos sociais, doações, dentre outros.

Diante da oferta desses benefícios aos clubes de futebol é natural que a sociedade procure mais informações acerca da gestão dessas entidades, sejam elas de quaisquer natureza, mas principalmente sobre a gestão dos recursos financeiros (Silva, Teixeira, \& Niyama, 2009).

Assim, em mais uma tentativa de profissionalizar e dar mais transparência à gestão dos clubes de futebol foi sancionada a Lei no 13.155 (2015), que estabelece o Programa de Modernização da Gestão e de Responsabilidade Fiscal do Futebol Brasileiro, conhecida também como Lei do PROFUT, que dentre outros aspectos estabelece princípios e práticas de responsabilidade fiscal, financeira, de gestão e institui parcelamento de débitos fiscais dos clubes de futebol com a União.

O PROFUT pode ser visto, então, como uma possibilidade de melhorar a gestão desses clubes, implicando diretamente nos seus desempenhos econômico-financeiro e esportivo. No entanto, o referido programa exigiu dessas entidades algumas contrapartidas, inclusive nas demonstrações contábeis, o que caracteriza o disclosure obrigatório.

Convém destacar que a Resolução CFC no 1429 (2013) do Conselho Federal de Contabilidade (CFC) aprovou a Interpretação Técnica Geral (ITG) no 2003, que dispõe sobre os procedimentos contábeis e regras de divulgação das entidades desportivas profissionais, além de expressar também que tais entidades devem seguir os Princípios e Normas de Contabilidade, assim como as Interpretações e Comunicados Técnicos editados pelo CFC. Portanto, os clubes de futebol devem divulgar informações financeiras em consonância com as práticas contábeis adotadas no Brasil.

Adicionalmente, o CPC, em seu Pronunciamento Técnico CPC 07 estabeleceu critérios de contabilização e divulgação de subvenções e assistências governamentais pelas entidades que se beneficiam deste tipo de ação do governo. Logo, a adesão ao PROFUT pelos clubes caracteriza-se como assistência governamental ao possibilitar o parcelamento de débitos fiscais com redução de multas, juros e encargos legais.

Recentemente, é notório o aumento do interesse de pesquisadores na divulgação das informações contábeis em clubes de futebol, especialmente em relação ao ativo intangível (Holanda, Meneses, Mapurunga, De Luca, \& Coelho, 2012; Maia, Cardoso, \& Ponte, 2013; Leite \& Pinheiro, 2014; Mota, Brandão, \& Ponte, 2016; Maia \& Vasconcelos, 2016; Figueiredo, Santos, \& Cunha, 2017). No 
entanto, estudos direcionados ao atendimento à Lei do PROFUT e à divulgação de informações sobre a assistência governamental nos clubes de futebol são ainda pouco conhecidos na literatura.

Considerando o disposto, a presente pesquisa busca responder ao seguinte questionamento: quais as mudanças percebidas no disclosure após a adesão, pelos clubes de futebol brasileiros, ao PROFUT e sua relação com o desempenho econômico-financeiro e esportivo? Assim, o estudo objetiva de forma geral investigar o nível de disclosure decorrente da adesão ao PROFUT pelos clubes de futebol brasileiros e sua relação com o desempenho econômico-financeiro e esportivo no decorrer dos anos de 2015 e 2016.

Especificamente, pretende-se (i) investigar o disclosure dos itens requeridos no CPC 07 (subvenções e assistência governamental) e na Lei 13.155/2015 (PROFUT), comparando os anos de 2015 e 2016; (ii) investigar se as variáveis de desempenho econômico-financeiro e esportivo estão correlacionadas ao nível de disclosure; e (iii) analisar a relação entre o desempenho econômico-financeiro e o desempenho esportivo.

Vale ressaltar que, tanto a assistência governamental, quanto as condições oferecidas pelo PROFUT, são incentivos para o desenvolvimento dos clubes. Nesse ponto, a pesquisa se justifica pela necessidade de prestação de contas, por parte dessas entidades, quanto ao retorno obtido com esses benefícios. Percebe-se ainda que pesquisas sobre essa temática são ainda pouco conhecidas na literatura, pois, em relação ao PROFUT, o fato de sua criação ser recente, reflete no reduzido número de estudos.

\section{FUNDAMENTAÇÃO TEÓRICA}

Neste capítulo discorre-se sobre o histórico da legislação aplicável aos clubes de futebol no Brasil envolvendo a problemática que motivou a presente pesquisa. Tal análise é complementada pela apresentação de um levantamento teórico o disclosure e os principais trabalhos envolvendo o tema aplicado às entidades esportivas.

\subsection{Legislação aplicada aos Clubes de Futebol}

Na década de 1990, os investimentos privados no esporte aumentavam no cenário internacional, desta forma foi necessário adequar a legislação brasileira à essa nova perspectiva (Silva et al., 2009). A Lei no 8.672 (1993), conhecida como Lei Zico, instituiu normas gerais sobre desportos alinhadas ao contexto econômico, vedando a intervenção estatal, por exemplo. No entanto, o ponto crucial da nova lei foi a faculdade das entidades desportivas transformarem-se em entidades comerciais com fins lucrativos (Lei n⿳0 8.672, 1993). Segundo Silva e Carvalho (2009) essa lei não foi bem aceita pelos dirigentes visto que o enquadramento neste novo conceito eliminaria uma série de vantagens fiscais que os clubes possuíam.

Devido à resistência dos dirigentes dos clubes em aderir à Lei Zico, foi sancionada a Lei ${ }^{\circ}$ 9.615 (1998), mais conhecida como Lei Pelé. Esta lei foi um marco importante para alteração da estrutura dos clubes. Foi extinta a figura do passe dos atletas causando um impacto financeiro significativo nos clubes, uma vez que ocasionou perda de receitas. Outro aspecto tratado foi a possibilidade dos clubes transformarem-se em empresas com um prazo para adaptação de dois anos, o que exigiu uma maior profissionalização da gestão.

Rezende e Dalmácio (2015) apontam que esse período de adaptação dos clubes gerou muita insatisfação aos dirigentes. Como forma de minimizar os conflitos foi editada e promulgada a Lei $\mathrm{n}^{\mathrm{o}}$ 9.940 (1999), que alargou o prazo para três anos. Posteriormente, e por pressão dos dirigentes, foi 
sancionada a Lei no 9.981 (2000) que alterou a Lei Pelé e apenas facultou a transformação em empresas.

Mais uma vez, os dirigentes resistiam à mudança da forma jurídica dessas entidades, pois se utilizavam delas para o atendimento de seus interesses pessoais como, por exemplo, fins eleitorais, conforme apontam Silva e Carvalho (2009). Dessa forma, era conveniente mantê-las como entidades sem fins lucrativos.

Em 2003, foi sancionada a Lei $n^{\circ} 10.672$ (2003), conhecida como Lei de Moralização do Futebol, que alterava alguns dispositivos da Lei Pelé. Dentre os quais, a inserção do princípio da transparência financeira e administrativa. Observando este princípio, os clubes passaram a ser obrigados a elaborar e divulgar suas demonstrações financeiras com base nos preceitos da Lei nº 6.404 (1976) após auditoria independente (Silva et al., 2009). Os clubes, então, passaram a divulgar suas demonstrações contábeis auditadas como forma de garantir a fidedignidade das informações (Holanda et al., 2012).

Num primeiro momento, as demonstrações contábeis dos clubes não permitiam a comparabilidade devido à ausência de uniformização das informações nelas contidas (Silva et al., 2009). Então, o CFC publicou a Resolução no 1.005 (2004) que aprovava a NBC T 10.13 sobre critérios específicos de registro e evidenciação contábil das entidades desportivas, pretendendo assim solucionar a dificuldade de comparação entre as demonstrações contábeis das diversas entidades atuantes nesse ramo (Bastos, Pereira, \& Tostes, 2007; Silva et al., 2009).

Vale destacar que, no cenário internacional, o Financial Fair Play foi aprovado pelo comitê executivo da UEFA no ano de 2009 com o objetivo de gerar um balanço financeiro positivo para os clubes, impedindo que essas entidades gastem mais do que arrecadam, reduzindo, assim, o nível de endividamento. Silva e Silva (2016) esclarecem que esse mecanismo prevê a aplicação de sanções para as entidades que não horarem seus compromissos financeiros, prática que melhora a sustentabilidade do futebol.

Posteriormente, no ano de 2015, foi sancionada a mais recente lei que trata das entidades profissionais de futebol. Trata-se da Lei de Responsabilidade Fiscal do Esporte (Lei $\left.{ }^{\circ} 13.155,2015\right)$ que, dentre outros aspectos, estabelece princípios e práticas de responsabilidade fiscal, financeira, de gestão e institui parcelamento de débitos fiscais com a União a partir da criação do Programa de Modernização da Gestão e de Responsabilidade Fiscal do Futebol Brasileiro (PROFUT), com o objetivo de promover a gestão transparente e democrática e o equilíbrio financeiro das entidades desportivas profissionais de futebol.

O PROFUT possibilita que os clubes que aderirem ao programa parcelem débitos na Secretaria da Receita Federal, Procuradoria Geral da Fazenda Nacional, Banco Central e Ministério do Trabalho. Em contrapartida, os clubes devem cumprir uma série de exigências para que possam se manter no programa, destacam-se as principais (a) regularidade das obrigações trabalhistas e tributárias federais correntes; (b) fixação do período do mandato de seu presidente ou dirigente máximo e demais cargos eletivos em até quatro anos, permitida uma única reeleição; (c) comprovação da existência e autonomia do conselho fiscal; (d) proibição de antecipação ou comprometimento de receitas futuras, salvo exceções; e (e) publicação das demonstrações contábeis padronizadas, separadamente, por atividade econômica e por modalidade esportiva, de modo distinto das atividades recreativas e sociais, após terem sido submetidas a auditoria independente (Lei $\mathrm{n}^{\mathrm{o}}$ 13.155, 2015). A 
Lei 13.155 (2015) ainda prevê penalidades esportivas em casos de não comprovação da regularidade fiscal perante a União, ao Fundo de Garantia por Tempo de Serviço (FGTS) e dos pagamentos de salários e contratos de imagem dos atletas.

O prazo para adesão pelos clubes optantes ao PROFUT era, inicialmente, até 30 de novembro de 2015, mas a Lei no 13.262 (2016) prorrogou o prazo até 31 de julho de 2016. Grande parte dos clubes do Campeonato Brasileiro de 2015 e 2016, amostra desta pesquisa, aderiu ao programa ainda no prazo inicial, tendo que, obrigatoriamente, elaborar demonstrações contábeis segundo os preceitos da Lei nº 13.155 (2015) já no exercício de 2015.

\subsection{Desempenho Econômico-Financeiro e Esportivo em clubes de futebol}

Apesar da criação de normas que estabelecem procedimentos para a estruturação das demonstrações contábeis, Souza, Sousa, Nascimento e Bernardes (2016) constatou que não há padronização por parte dos clubes de futebol no processo de elaboração dos seus demonstrativos financeiros, logo essas entidades acabam não evidenciando pontos primordiais para a tomada de decisão.

Diante da necessidade de existência de informações que possibilitem uma tomada de decisão mais assertiva por parte dos investidores vale ressaltar a importância dos indicadores de avaliação de desempenho organizacional que são instrumentos gerenciais amplamente abordados na Contabilidade.

Nesse sentido, para Coy e Dixon (2004) um índice compreende, num simples número, um conjunto de informações que se pretende mensurar, que determina uma pontuação para o desempenho organizacional. No caso do futebol, ele pode sinalizar a conduta exercida pelos dirigentes na gestão dos clubes e pode ser usado, pelos stakeholders, como ferramenta para o monitoramento da gestão.

Os indicadores de desempenho são ferramentas que demonstram não somente a situação econômico-financeira, mas também retratam como as entidades estão trabalhando sua produtividade, qualidade e estratégia, sendo, dessa forma, indispensáveis para a avaliação da situação patrimonial (Oliveira, Viana Júnior, Ponte, \& Domingos, 2017). De modo amplo, os indicadores de desempenho relacionados às entidades desportivas, como é o caso dos clubes de futebol, podem ser resumidos em econômico-financeiros e esportivos.

Os indicadores econômico-financeiros revelam a situação econômica da empresa, estão relacionados com os resultados econômicos e expressam o desempenho voltado à geração de caixa (Oliveira et al., 2017). Dentre os principais indicadores da performance econômico-financeira destacamse a rentabilidade, representada, por exemplo, pelo o ROA (Holanda, 2015), ROE (Maçambanni, Souza, Souza, \& Murcia, 2012; Múrcia \& Santos, 2010; Salotti \& Yamamoto, 2008), o tamanho, que pode ser representado pelo total do ativo (Holanda, 2015; Maçambanni et al., 2012; Benin, Diehl, \& Marquezan, 2016; Galvão \& Miranda, 2016) e o endividamento, sistematizado através do quociente entre o passivo e o ativo total (Holanda, 2015; Benin et al., 2016).

Os indicadores de desempenho esportivo estão ligados aos resultados obtidos pelos clubes de futebol na execução dos torneios, dentre os quais pode-se destacar a série e a variação da série nos campeonatos (Rezende \& Dalmácio, 2015), a classificação ou pontuação obtida nos campeonatos (Mota et al., 2015; Silva et al., 2009; Leite \& Pinheiro, 2013), a média de pagantes por torneio, dentre outros. 
O estudo realizado por Rezende e Dalmácio (2015), por exemplo, avaliou a relação entre governança corporativa e os desempenhos econômico-financeiro e esportivo. Como proxies para o desempenho econômico-financeiro utilizou o lucro e receita dos anos de 2006 e 2007. Já para o desempenho esportivo foram utilizadas a pontuação obtida no campeonato, a presença nas séries A, B e C e a estimativa do número de torcedores de cada um dos 27 clubes de futebol analisados. Como resultado, os autores identificaram a existência de relação significante e positiva entre a governança corporativa e os indicadores de performance econômico-financeira e esportiva.

Tendo em vista o escopo delineado, percebe-se que o desempenho dos clubes de futebol acaba sendo condicionado à percepção dos torcedores. Estes, por sua vez, investem (como sócios torcedores ou mesmo compradores de ingressos para partidas) e atraem outras modalidades de receitas como aquelas destinadas à patrocínio e/ou divulgação.

Fica evidente, então, a importância do disclosure para a melhora da qualidade das informações contábeis divulgadas pelos clubes de futebol. As informações contábeis de qualidade podem, por sua vez, impactar na melhora dos indicadores de desempenho dessas entidades na medida em geram maior confiabilidade por parte dos investidores e da sociedade em geral.

\subsection{Disclosure em Clubes de Futebol}

As demonstrações contábeis são as principais ferramentas para que a Contabilidade cumpra seu papel de prover informações relevantes e fidedignas para a tomada de decisão. É objetivo das demonstrações contábeis fornecer informações sobre a posição patrimonial e financeira da entidade, além de apresentar os resultados da atuação da administração e sua capacidade de prestar contas quanto aos recursos que lhe foram confiados (Fundação Instituto de Pesquisas Contábeis, Atuariais e Financeiras (FIPECAFI, 2010).

Pesquisas anteriores como as realizadas por Santos e Calixto (2010) e Mapurunga, Morais, Ponte, Rebouças e Carneiro (2015) já objetivaram calcular um índice para o nível de disclosure corporativo utilizando para tanto dois cálculos diferentes, um deles tolerante e o outro rigoroso. $\mathrm{O}$ índice tolerante leva em consideração que os itens não reportados pelas entidades não lhes são aplicáveis, diferentemente do índice rigoroso.

No contexto esportivo, Silva e Carvalho (2009, p. 100) “é função da Contabilidade fornecer informações que evidenciem a situação dos clubes de futebol e que satisfaçam a expectativa de usuários e investidores na avaliação do desempenho financeiro e operacional desse tipo de organização". Nesse sentido, convém ressaltar que os clubes de futebol foram obrigados pela Lei n 10.672 (2003) a divulgar suas demonstrações contábeis baseadas na Lei nº 6.404 (1976), Lei das Sociedades por Ações, porém, fez-se necessário a publicação pelo CFC da Resolução no 1005 (2004) para padronizar as informações constantes nas demonstrações dos clubes.

Segundo Bastos, Pereira e Tostes (2007) pode-se destacar acerca da Resolução nº 1005 (2004) do CFC a exigência do registro dos gastos com formação de atletas em conta específica do imobilizado, gastos com contratação e renovação de contratos de atletas profissionais pelo valor pago ou incorrido, amortização dos gastos e direitos contratuais de acordo com o prazo do contrato firmado, verificação da possibilidade de recuperação econômico-financeira do valor líquido contábil do custo de formação registrado no imobilizado (impairment test), dentre outros aspectos. Essa resolução foi 
marco importante na padronização das demonstrações contábeis dos clubes que até então tinham o subjetivismo como característica.

Em 2013, o CFC publicou a Resolução no 1429 (2013) que dispõe sobre procedimentos e regras de divulgação das entidades desportivas profissionais, já como uma modernização da Resolução $\mathrm{n}^{\mathbf{o}}$ 1005 (2004). O ponto mais relevante de alteração refere-se ao registro de atletas como ativo intangível e não mais como imobilizado como tratava a Resolução no 1005 (2004), numa clara adequação das entidades desportivas à Lei no 11.638 (2007), que por sua vez inseria o Brasil no rol dos países que seguem as normas internacionais de Contabilidade.

Segundo Lucas Silva e Leonardo Silva (2016), a Lei de Responsabilidade Fiscal do Esporte surge da necessidade de se estabelecer práticas de responsabilidade fiscal, financeira e de gestão transparente das entidades desportivas de futebol brasileiro, uma vez que a União, como maior credora, notou que algo devia ser feito para atenuar os graves problemas financeiros pelos clubes de futebol brasileiros.

A Lei $n^{\circ} 13.155$ (2015) passou a exigir dos clubes que aderiram ao PROFUT maior transparência de suas atividades financeiras como contrapartida aos benefícios fiscais recebidos com a redução de multas, juros e encargos legais. Neste aspecto, a lei exige que as demonstrações contábeis dos clubes explicitem, além de outros valores exigidos pelas normas contábeis e pela legislação: (a) as receitas de transmissão e de imagem; (b) as receitas de patrocínios, publicidade, luva e marketing; (c) as receitas com transferência de atletas; (d) as receitas de bilheteria; (e) as receitas e despesas com atividades sociais da entidade; (f) as despesas totais com modalidade desportiva profissional; (g) as despesas com pagamento de direitos econômicos de atletas; (h) as despesas com pagamento de direito de imagem de atletas; (i) as despesas com modalidades desportivas não profissionais; e (j) as receitas decorrentes de repasses de recursos públicos de qualquer natureza, origem e finalidade.

Nesse sentido, um dos pontos mais relevantes da Lei $\mathrm{n}^{\circ} 13.155$ (2015) é o parcelamento de débitos dos clubes na Secretaria da Receita Federal, Procuradoria Geral da Fazenda Nacional, Banco Central e Ministério do Trabalho e Emprego em até 240 parcelas com redução de $70 \%$ (setenta por cento) das multas, $40 \%$ (quarenta por cento) dos juros e 100\% (cem por cento) dos encargos legais. Esse processo acabou impactando as demonstrações contábeis dos clubes de futebol no ano de 2015, situação que demanda maior cuidado no processo de divulgação.

O PROFUT, então, enquadra-se como assistência governamental na modalidade de empréstimo subsidiado, por possibilitar o parcelamento dos débitos fiscais dos clubes de futebol com redução de juros, multas e encargos legais. Dessa forma, além dos itens exigidos na Lei nº 13.155 (2015) os clubes devem divulgar informações conforme exigência do CPC 07.

Em 2010, foi aprovado o CPC 07 (R1) que modificou alguns pontos do CPC 07. Dentre os quais as informações que as entidades devem divulgar que são: (a) a política contábil adotada para as subvenções governamentais e assistências governamentais, incluindo os métodos de apresentação adotados nas demonstrações contábeis; (b) a natureza e a extensão das subvenções ou assistências governamentais reconhecidas nas demonstrações contábeis e uma indicação de outras formas de assistência governamental de que a entidade tenha se beneficiado; e (c) condições a serem regularmente satisfeitas e outras contingências ligadas à assistência governamental que tenha sido reconhecida. 
Estudos anteriores concluíram que as empresas brasileiras apresentavam um baixo nível de evidenciação das subvenções e assistências governamentais em suas demonstrações contábeis. Fonteles (2013) estudou a relação entre assistências governamentais e disclosure socioambiental e identificou que empresas beneficiadas com incentivos fiscais não divulgavam em maior nível informações sobre Responsabilidade Social Corporativa. Loureiro, Gallon e De Luca (2011) investigaram a evidenciação das subvenções e assistências governamentais e a rentabilidade das maiores empresas brasileiras, verificando que o nível de atendimento dos requisitos de divulgação do CPC 07 era relativamente baixo em 2008 e 2009 e que nenhuma das empresas pesquisadas divulgou todos os itens recomendados pelo CPC 07.

No entanto, pesquisas sobre disclosure e assistência governamental em clubes de futebol são ainda pouco conhecidas na literatura, embora refinanciamento de débitos fiscais para os clubes de futebol não seja novidade. Em relação ao PROFUT, o fato de ser relativamente recente sua criação, justifica-se o reduzido número de estudos envolvendo o tema.

Com relação aos trabalhos anteriores que discorrem especificamente sobre o disclosure de informações em clubes de futebol pode-se destacar a pesquisa de Silva et al. (2009) que identificaram a relação positiva entre receitas recebidas pelos clubes e o nível de evidenciação das informações contábeis. Rezende, Dalmácio e Salgado (2010) chegaram à conclusão semelhante, constatando que o nível de evidenciação tem relação com o tamanho econômico do clube e com os mecanismos de enforcement. Nesse sentido, a partir dos resultados dos estudos apresentados, têm-se evidências de que a performance econômico-financeira dessas entidades pode estar relacionada com o nível de divulgação.

Já o estudo de Leite e Pinheiro (2014) verificou que quanto melhor o desempenho no Campeonato Brasileiro e quanto maior as receitas totais, maior também era o nível de evidenciação do intangível nas demonstrações contábeis dos clubes analisados. Galvão e Miranda (2016) analisaram especificamente a evidenciação de informações acerca do valor dos atletas nos relatórios contábeis, concluindo que a maioria dos clubes evidenciam informações segundo a ITG 2003 e que há indícios de relação entre o disclosure e o valor dos atletas. As pesquisas relatadas possibilitam, então, inferir a existência de possível relação entre a performance esportivas dos clubes de futebol e o nível de divulgação.

Diante do escopo desenhado através dos estudos anteriores previamente apresentados, delineou-se como hipótese para a pesquisa que $(\mathrm{H} 1)$ há relação entre o disclosure e os desempenhos econômico-financeiro e esportivo no período analisado.

Adicionalmente, e considerando que a Lei no․ 13.155 (2015) acaba impulsionando uma melhora na gestão dos clubes de futebol, com consequente aumento da transparência nas informações econômico-financeiras, além da influência de uma possível curva de aprendizagem desses clubes a partir do PROFUT, pode-se também estabelecer como hipótese que (H2) houve aumento do nível de disclosure entre os anos de 2015 e 2016.

\section{PROCEDIMENTOS METODOLÓGICOS}

Trata-se de um estudo descritivo, uma vez que tem por objetivo a identificação, registro e análise dos aspectos de um objeto, cena, fato, acontecimento, fenômeno ou processo, para, a partir 
de então, identificar deficiências (Polit, Beck, \& Hungler, 2011), nesse caso, o nível de disclosure dos clubes de futebol e os indicadores de desempenho econômico-financeiros e esportivos.

Com relação à abordagem, o presente estudo pode ser classificado como quantitativo, a qual está associada ao tratamento estatístico e inferencial aplicado sobre os dados coletados. Roesch (2005) destaca que a pesquisa quantitativa é aquela que busca medir relações entre variáveis ou avaliar o resultado de algum sistema ou projeto. Vale ressaltar que a distinção entre as técnicas qualitativas e quantitativas nem sempre é clara e, portanto, o delineamento da pesquisa se faz imprescindível para garantir uma boa interpretação dos resultados.

A amostra da pesquisa foi constituída por todos os clubes de futebol participantes do Campeonato Brasileiro que aderiram ao PROFUT em 2015 e que permaneceram aderentes em 2016. A amostra inicial foi composta por 76 observações para os dois anos mencionados e os relatórios contábeis utilizados na pesquisa foram coletados através dos endereços eletrônicos dos clubes de futebol selecionados. O Quadro 1 apresenta a relação de clubes analisados, suas respectivas séries no lapso temporal estudado.

Quadro 1 - Clubes participantes da pesquisa e séries nos anos de 2015 e 2016

\begin{tabular}{|l|c|c|}
\hline \multirow{2}{*}{\multicolumn{1}{c|}{ Clube }} & \multicolumn{2}{c|}{ Série } \\
\cline { 2 - 3 } & 2015 & $\mathbf{2 0 1 6}$ \\
\hline ABC-RN & B & C \\
\hline América-MG & B & A \\
\hline ASA-AL & C & C \\
\hline Atlético-GO & B & B \\
\hline Atlético-MG & A & A \\
\hline Atlético-PR & A & A \\
\hline Avaí-SC & A & B \\
\hline Bahia-BA & B & B \\
\hline Botafogo-PB & C & C \\
\hline Botafogo-RJ & B & A \\
\hline Brasil de Pelotas-RS & C & B \\
\hline Caxias-RS * & C & D \\
\hline Ceará-CE & B & B \\
\hline
\end{tabular}

\begin{tabular}{|l|c|c|}
\hline \multirow{2}{*}{\multicolumn{1}{c|}{ Clube }} & \multicolumn{2}{c|}{ Série } \\
\cline { 2 - 3 } & 2015 & $\mathbf{2 0 1 6}$ \\
\hline Confiança-SE * & C & C \\
\hline Corinthians-SP & A & A \\
\hline Curitiba-PR & A & A \\
\hline Cruzeiro-MG & A & A \\
\hline Figueirense-SC & A & A \\
\hline Flamengo-RJ & A & A \\
\hline Fluminense-RJ & A & A \\
\hline Fortaleza-CE & C & C \\
\hline Goiás-GO & A & B \\
\hline Grêmio-RS & A & A \\
\hline Internacional-RS & A & A \\
\hline Joinville-SC & A & B \\
\hline Juventude-RS & C & C \\
\hline
\end{tabular}

\begin{tabular}{|l|c|c|}
\hline \multirow{2}{*}{\multicolumn{1}{|c|}{ Clube }} & \multicolumn{2}{c|}{ Série } \\
\cline { 2 - 3 } & 2015 & 2016 \\
\hline Londrina-PR $^{*}$ & C & B \\
\hline Luverdense-MT $^{*}$ & B & B \\
\hline Náutico-PE & B & B \\
\hline Paraná-PR & B & B \\
\hline Paysandu-PA & B & B \\
\hline Ponte Preta-SP & A & A \\
\hline Santa Cruz-PE & B & A \\
\hline Santos-SP & A & A \\
\hline São Paulo-SP & A & A \\
\hline Tupi-MG * & C & B \\
\hline Vasco da Gama-RJ & A & B \\
\hline Vitória-BA & B & A \\
\hline
\end{tabular}

Nota. $\left({ }^{*}\right)$ representa os clubes que não divulgaram, em pelo menos um dos anos estudados, suas demonstrações financeiras. Fonte: Confederação Brasileira de Futebol (2017).

É importante estabelecer que, os clubes nos quais os relatórios contábeis não foram divulgados nos períodos de 2015 e 2016, foram eliminados para efeito de análise dos dados e resultados. Nesse sentido, a amostra final do estudo foi composta por 64 observações (32 diferentes clubes), conforme Tabela 1.

Tabela 1 - Constituição da amostra da pesquisa

\begin{tabular}{l|c}
\hline Descrição & \multicolumn{2}{c}{ Quantidade } \\
\hline Amostra Inicial (anos 2015 e 2016) & 76 \\
\hline ( - ) Clubes que não divulgaram informações (anos 2015 e 2016) & $(12)$ \\
\hline Amostra Final do estudo (32clubes) & 64 \\
\hline
\end{tabular}

Fonte: Dados da pesquisa (2016).

A técnica de análise adotada no estudo foi a de análise descritiva, conhecida por se utilizar de técnicas da estatística descritiva que compreende o manejo dos dados para resumi-los ou descrevêlos, sem ir além, isto é, sem procurar inferir qualquer coisa que ultrapasse os próprios dados (Freund \& Simon, 2000). A operacionalização das variáveis selecionadas para representar os desempenhos econômico-financeiro e esportivo, além do disclosure, encontram-se dispostas no Quadro 2.

Quadro 2 - Quadro síntese das variáveis adotadas no estudo 


\begin{tabular}{|c|c|c|c|c|}
\hline & Variável & Sigla & Proxy & Estudos Anteriores \\
\hline \multirow{4}{*}{ 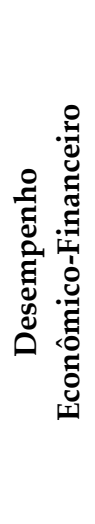 } & \multirow[b]{2}{*}{ Rentabilidade } & ROA & (Lucro Líquido/Total do Ativo) & Holanda (2015) \\
\hline & & ROE & (Lucro Líquido/Patrimônio Líquido) & $\begin{array}{l}\text { Maçambanni, Souza, Souza e } \\
\text { Murcia (2012); Múrcia e Santos } \\
\text { (2010); Salotti e Yamamoto } \\
\text { (2008) }\end{array}$ \\
\hline & Tamanho & TAM & Ln (Total do Ativo) & $\begin{array}{l}\text { Holanda (2015); Maçambanni et } \\
\text { al. (2012); Benin, Diehl e Mar- } \\
\text { quezan (2016); Galvão e Mi- } \\
\text { randa (2016) }\end{array}$ \\
\hline & Endividamento & END & (Passivo/Ativo Total) & $\begin{array}{l}\text { Holanda (2015); Benin et al. } \\
\text { (2016) }\end{array}$ \\
\hline \multirow{4}{*}{ 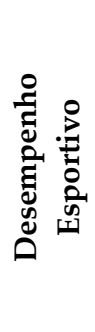 } & Série & SER & De acordo com a classificação final & Rezende e Dalmácio (2015) \\
\hline & $\begin{array}{l}\text { Variação da Sé- } \\
\text { rie }\end{array}$ & VSE & $\begin{array}{l}\text { Dummy, onde recebe } 0 \text { se não houve variação da } \\
\text { série entre } 2015 \text { e } 2016 \text { e } 1 \text { caso contrário. }\end{array}$ & - \\
\hline & $\begin{array}{l}\text { Classificação no } \\
\text { Campeonato }\end{array}$ & CLA & $\begin{array}{l}\text { Quantidade de pontos obtidos, coletado no website } \\
\text { da Confederação Brasileira de Futebol (CBF) }\end{array}$ & $\begin{array}{l}\text { Mota et al. (2015); Silva et al. } \\
\text { (2009); Leite e Pinheiro (2013) }\end{array}$ \\
\hline & $\begin{array}{l}\text { Média de Pa- } \\
\text { gantes }\end{array}$ & MPG & $\begin{array}{l}\text { Total de ingressos vendidos/ Total de jogos realiza- } \\
\text { dos }\end{array}$ & - \\
\hline \multirow{2}{*}{ 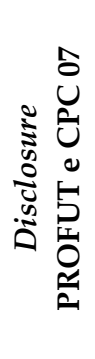 } & $\begin{array}{l}\text { Índice } 1 \text { (rigo- } \\
\text { roso) }\end{array}$ & N1 & $\begin{array}{l}\text { Divisão do número de itens atendidos, pelo nú- } \\
\text { mero de itens requeridos, sendo o quociente sub- } \\
\text { traído do número de itens não aplicáveis à em- } \\
\text { presa. }\end{array}$ & $\begin{array}{l}\text { Holanda (2015); } \\
\text { Mapurunga et al. (2015) }\end{array}$ \\
\hline & $\begin{array}{l}\text { Índice } 2 \text { (tole- } \\
\text { rante) }\end{array}$ & N2 & $\begin{array}{l}\text { Divisão do número de itens atendidos, pelo nú- } \\
\text { mero de itens requeridos, sendo o quociente sub- } \\
\text { traído do número de itens não aplicáveis e também } \\
\text { do número de itens não informados. }\end{array}$ & $\begin{array}{l}\text { Holanda (2012); } \\
\text { Mapurunga et al. (2015) }\end{array}$ \\
\hline
\end{tabular}

Fonte: Elaborado pelo autor (2017).

Conforme exemplificado através do Quadro 2, as variáveis de desempenho foram segmentadas em duas categorias, envolvendo variáveis de desempenho econômico-financeiro e de desempenho esportivo. Com relação ao disclosure, esta pesquisa optou por considerar dois índices, de acordo com Santos e Calixto (2010) e Mapurunga, Morais, Ponte, Rebouças e Carneiro (2015), sendo um deles rigoroso (índice 1) e outro tolerante (índice 2). Esses índices foram calculados através de uma métrica para atendimento aos itens de divulgação constantes na Lei do PROFUT (Lei no $13.155,2015$ ) e também no CPC 07 (Subvenções e Assistência Governamental). O Quadro 3 estabelece os itens de divulgação considerados na métrica desenvolvida para o cálculo do disclosure.

Quadro 3 - Itens de divulgação utilizados para cálculo do disclosure

Itens de Divulgação - CPC 07

\begin{tabular}{|l|}
\hline Divulgar a política contábil adotada para as subvenções governamentais. \\
\hline Divulgar os métodos de apresentação adotados nas Demonstrações Contábeis. \\
\hline Divulgar a natureza das subvenções ou assistências governamentais reconhecidas nas Demonstrações Contábeis. \\
\hline Divulgar a extensão das subvenções ou assistências governamentais reconhecidas nas Demonstrações Contábeis. \\
\hline
\end{tabular}




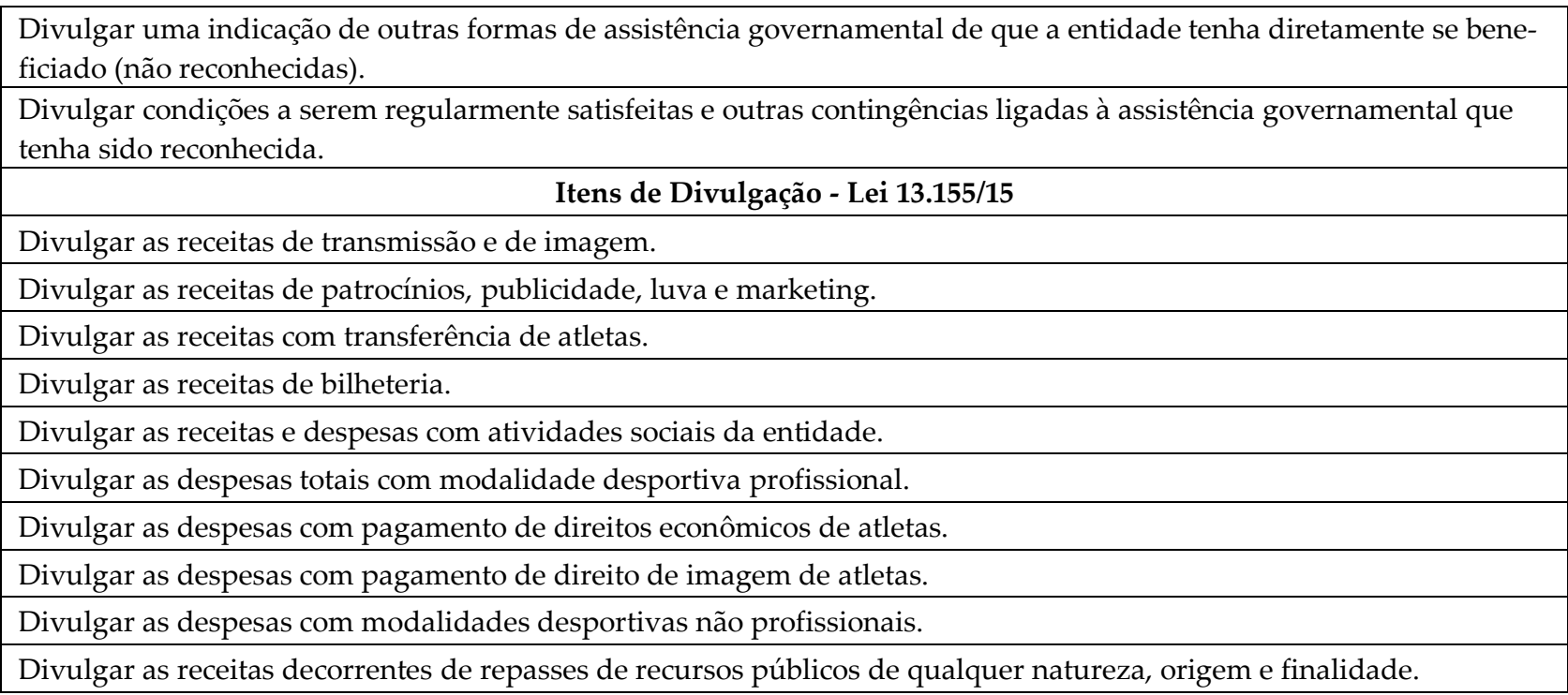
Fonte: Pronunciamento Técnico CPC 07 (2010) e Lei 13.155 (2015).

Diante do escopo apresentado, vale ressaltar que o estudo buscou inovar com a adoção de variáveis ainda não exploradas no que refere ao desempenho esportivo, como é o caso da média de pagantes e a variação da série (rebaixamento ou acesso dos clubes). Além disso, como diferencial, a pesquisa relaciona, além do desempenho econômico-financeiro, o desempenho esportivo dos clubes em conjunto com o nível de disclosure.

Os dados utilizados relativos ao desempenho econômico-financeiro foram coletados por meio das demonstrações financeiras dos clubes e as variáveis de desempenho esportivo foram coletadas no website da Confederação Brasileira de Futebol [CBF], no campo "Campeonato Brasileiro" para a variável relativa à variação da série. Já para a variável relacionada com a média de pagantes, observou-se o site do GloboEsporte.Com cujo acesso foi realizado em 08/09/2017.

O presente estudo tem por finalidade analisar as variáveis relacionadas ao desempenho econômico-financeiro, de acordo com a literatura levantada, e também as variáveis de desempenho esportivo, com o intuito de investigar a correlação com o nível de disclosure. Para tanto, a pesquisa utilizou como técnica estatística o teste de diferença entre médias, para comparar o disclosure dos períodos levantados. Para verificar a relação entre as variáveis do estudo foi utilizada a Análise de Correspondência Múltipla ou Análise de Homogeneidade (HOMALS) que possibilitou a associação das variáveis "Desempenho Econômico-Financeiro", "Desempenho Esportivo" e "Disclosure" em função dos seus níveis que foram segregados em baixo, médio-baixo, médio-alto e alto de acordo com a segmentação em quartis. Para Fávero, Belfiore, Silva e Chan (2009), esse procedimento possibilita analisar as correspondências de mais de duas variáveis com diferentes números de níveis.

É importante ressaltar que os dados coletados neste estudo, com relação às variáveis de desempenho econômico-financeiro e esportivo, quanto no que tange ao nível de disclosure, foram processados com a utilização de planilhas eletrônicas via Microsoft Excel e do software estatístico Statistical Package for the Social Science (SPSS).

\section{RESULTADOS}

Inicialmente, a presente pesquisa investigou as variáveis levantadas para os desempenhos econômico-financeiro e esportivo, além dos níveis de disclosure calculados, comparando os anos de 2015 e 2016. Os dados obtidos foram extraídos das demonstrações contábeis dos clubes de futebol que aderiram ao PROFUT em 2015, a partir dos quais se procedeu a análise descritiva e inferencial, conforme apresenta a Tabela 2. 
Tabela 2 - Estatística descritiva e inferencial

\begin{tabular}{|c|c|c|c|c|c|c|}
\hline Ano & Variável & Média & Mediana & Desvio Padrão & Mínimo & Máximo \\
\hline \multirow[t]{7}{*}{2015} & Média de Pagantes & 13015,613 & 13189,000 & 8404,856 & 1796,000 & 34149,000 \\
\hline & Rentabilidade (ROA) &,- 057 &,- 033 &, 530 & $-2,248$ &, 964 \\
\hline & Rentabilidade (ROE) &,- 124 &,- 045 & 481 & $-1,204$ & ,936 \\
\hline & Endividamento & 2,300 & 1,117 & 3,848 &, 269 & 21,593 \\
\hline & Ln Tamanho & 18,328 & 18,609 & 2,068 & 12,382 & 21,025 \\
\hline & Nível de Disclosure N1 &, 591 & ,625 &, 219 & 0,000 &, 875 \\
\hline & Nível de Disclosure N2 & ,546 & ,588 & ,224 & 0,000 & 875 \\
\hline \multirow[t]{7}{*}{2016} & Média de Pagantes & 11206,242 & 8902,000 & 7543,948 & 1831,000 & 28764,000 \\
\hline & Rentabilidade (ROA) &,- 020 &, 003 &, 271 & $-1,301$ &, 317 \\
\hline & Rentabilidade (ROE) & $-2,376$ &,- 022 & 9,343 & $-47,384$ & ,631 \\
\hline & Endividamento & 2,033 & 1,196 & 3,094 & ,267 & 17,303 \\
\hline & Ln Tamanho & 18,247 & 18,613 & 2,175 & 12,699 & 21,495 \\
\hline & Nível de Disclosure N1 &, 544 & ,625 &, 286 & 0,000 &, 875 \\
\hline & Nível de Disclosure N2 &, 503 & ,588 & ,276 & 0,000 & ,824 \\
\hline
\end{tabular}

Nota. $\mathrm{N}=64$

Fonte: Dados da pesquisa (2017).

De acordo com a Tabela 2, verifica-se uma redução na média de pagantes quando comparados os anos de 2015 e 2016. O mesmo se percebe para as variáveis Rentabilidade (ROE), Endividamento, Nível de Disclosure N1 (índice rigoroso) e Nível de Disclosure N2 (índice tolerante). Percebe-se ainda maior variabilidade nas médias de Rentabilidade, (ROA), Tamanho e Média de Pagantes. No que se refere ao nível de disclosure, que foi calculado conforme métricas definidas no Quadro 1, constata-se baixa variabilidade em ambos os índices calculados, o que pode indicar a redução no nível de divulgação quando comparados os dois períodos, indicando que os clubes que aderiram ao PROFUT em 2015 e permaneceram em 2016 não aumentaram o nível de disclosure.

Considerando que este estudo busca investigar a aderência aos requisitos de divulgação constantes no CPC 07 e na Lei $n^{\circ} 13.155$ (2015) para os clubes de futebol que aderiram ao PROFUT, optouse pela realização de teste de diferença entre médias para ambos os índices (N1 e N2), comparando os anos de 2015 e 2016. Nesse sentido, procedeu-se a realização do teste de normalidade para as variáveis N1 e N2, análise necessária para verificar o comportamento dos dados levantados. Como resultado preliminar da análise do disclosure calculado para cada clube, apresenta-se a Tabela 3.

Tabela 3 - Disclosure calculado para os clubes de futebol em 2015 e 2016

\begin{tabular}{|c|c|c|c|c|c|c|c|c|c|}
\hline \multirow{2}{*}{ Clube } & \multicolumn{2}{|c|}{2015} & \multicolumn{2}{|c|}{2016} & \multirow{2}{*}{ Clube } & \multicolumn{2}{|c|}{2015} & \multicolumn{2}{|c|}{2016} \\
\hline & N1 & N2 & N1 & N2 & & N1 & N2 & N1 & N2 \\
\hline ABC-RN & $\mathrm{N} / \mathrm{A}$ & $\mathrm{N} / \mathrm{A}$ & 0,000 & 1,000 & Fluminense-RJ & 0,813 & 0,813 & 0,813 & 0,813 \\
\hline América-MG & 0,313 & 4,313 & 0,625 & 1,625 & Fortaleza-CE & 0,000 & 0,000 & 0,437 & 0,563 \\
\hline ASA-AL & 0,250 & 2,250 & 0,313 & 2,313 & Goiás-GO & 0,750 & 1,750 & 0,750 & 1,750 \\
\hline Atlético-GO & 0,375 & 2,375 & 0,000 & 2,000 & Grêmio-RS & 0,625 & 2,625 & 0,625 & 2,625 \\
\hline Atlético-MG & 0,813 & 1,813 & 0,813 & 1,813 & Internacional-RS & 0,750 & 1,750 & 0,750 & 1,750 \\
\hline Atlético-PR & 0,750 & 1,750 & 0,750 & 1,750 & Joinville-SC & 0,625 & 2,625 & 0,688 & 2,688 \\
\hline Avaí-SC & 0,750 & 2,750 & 0,688 & 2,688 & Juventude-RS & 0,438 & 4,438 & 0,438 & 4,438 \\
\hline
\end{tabular}




\begin{tabular}{|c|c|c|c|c|c|c|c|c|c|}
\hline Bahia-BA & 0,875 & 0,875 & 0,813 & 1,813 & Náutico-PE & 0,000 & 3,000 & 0,000 & 3,000 \\
\hline Botafogo-PB & N/A & N/A & 0,188 & 2,188 & Paraná-PR & $\mathrm{N} / \mathrm{A}$ & $\mathrm{N} / \mathrm{A}$ & 0,500 & 4,500 \\
\hline Botafogo-RJ & 0,750 & 1,750 & 0,750 & 1,750 & Paysandu-PA & 0,125 & 5,125 & 0,438 & 4,438 \\
\hline Brasil de Pelotas-RS & 0,188 & 5,188 & 0,188 & 5,188 & Ponte Preta-SP & 0,625 & 2,625 & 0,563 & 3,563 \\
\hline Ceará-CE & 0,563 & 2,563 & 0,625 & 2,625 & Santa Cruz-PE & 0,250 & 2,250 & 0,250 & 2,250 \\
\hline Corinthians-SP & 0,750 & 0,750 & 0,750 & 0,750 & Santos-SP & 0,750 & 1,750 & 0,750 & 1,750 \\
\hline Coritiba-PR & 0,875 & 1,875 & 0,875 & 1,875 & São Paulo-SP & 0,750 & 1,750 & 0,750 & 1,750 \\
\hline Cruzeiro-MG & 0,625 & 1,625 & 0,813 & 1,813 & Vasco da Gama-RJ & 0,625 & 1,625 & 0,625 & 1,625 \\
\hline Figueirense-SC & 0,563 & 2,563 & 0,500 & 3,500 & Vitória-BA & 0,625 & 1,625 & 0,563 & 1,563 \\
\hline Flamengo-RJ & 0,813 & 0,813 & 0,813 & 0,813 & & & & & \\
\hline
\end{tabular}

Nota. N1 = Disclosure Nível 1 (rigoroso), N2 = Disclosure Nível 2 (tolerante)

Fonte: Dados da pesquisa (2017).

Considerando os níveis de disclosure apresentados na Tabela 3 e a partir dos resultados dos testes de normalidade de Kolmogorov-Smirnov e Shapiro-Wilk foi possível identificar que os dados coletados para as variáveis N1 e N2 não apresentam distribuição normal (Sig. <0,05). Assim, o teste não paramétrico de Mann-Whitney apresentou-se como mais adequado para o perfil de dados obtidos (Fávero et al., 2009), conforme apresentado na Tabela 4.

Tabela 4 - Testes de média

\begin{tabular}{l|r|r}
\hline \multicolumn{1}{c|}{ Estatística } & Nível de Disclosure N1 & \multicolumn{1}{c}{ Nível de Disclosure N2 } \\
\hline U de Mann-Whitney & 494,000 & 492,000 \\
\hline Wilcoxon W & 1055,000 & 1053,000 \\
\hline Z &,- 237 &,- 263 \\
\hline Significância Sig. (2 extremidades) &, 812 &, 792 \\
\hline
\end{tabular}

Nota. Variável de Agrupamento: Ano

Fonte: Dados da pesquisa (2017).

Com base na Tabela 4, não se percebem diferenças estatisticamente significantes quanto aos níveis de disclosure quando comparados os anos de 2015 e 2016 (Sig. > 0,05). Mota et al. (2016) estudaram materialidade e disclosure dos ativos intangíveis dos clubes da Série A de 2010 a 2012 e observaram níveis crescentes de disclosure. Já Figueiredo, Santos e Cunha (2017) estudaram, em termos gerais, o nível de disclosure em 25 clubes de futebol brasileiros de 2011 a 2015 e constataram melhoria tímida no índice de evidenciação dos clubes. Nesse sentido, pode-se afirmar que os clubes de futebol brasileiros não evoluíram em relação à divulgação contábil e ao atendimento das diretrizes estabelecidas pela Lei 13.155 (2015) e pelo CPC 07 entre 2015 e 2016. Desse modo, percebe-se que nem mesmo os mecanismos de enforcement foram incentivos suficientes para melhoria da divulgação pelos clubes analisados.

No que se refere ao relacionamento entre os indicadores econômico-financeiros, de desempenho esportivo e a evidenciação contábil dos clubes selecionados para esta pesquisa, levando ainda em consideração a normalidade dos dados analisados, procedeu-se o teste de correlação de Pearson, cujos dados são apresentados na Tabela 5.

Tabela 5 - Correlação entre as variáveis

\begin{tabular}{l|l|r|r|r|r|r|r|r}
\hline \multicolumn{2}{l|}{} & \multicolumn{1}{c}{ MPG } & \multicolumn{1}{c}{ ROA } & \multicolumn{1}{c}{ ROE } & \multicolumn{1}{c}{ END } & \multicolumn{1}{c}{ TAM } & \multicolumn{1}{c}{ DN1 } & \multicolumn{1}{c}{ DN2 } \\
\hline \multirow{2}{*}{ MPG } & Correlação de Pearson & 1,000 &, $248^{*}$ &, 049 &,$- 260^{*}$ &, $567^{* *}$ &, $514^{* *}$ &, $551^{* *}$ \\
\cline { 2 - 9 } & Sig. (2 extremidades) & &, 048 &, 702 &, 038 &, 000 &, 000 &, 000 \\
\hline \multirow{2}{*}{ ROA } & Correlação de Pearson &, $248^{*}$ & 1,000 &, 022 &,$- 685^{* *}$ &, $500^{* *}$ &, $347^{* *}$ &, $359^{* *}$ \\
\cline { 2 - 9 } & Sig. (2 extremidades) &, 048 & &, 864 &, 000 &, 000 &, 005 &, 004 \\
\hline \multirow{2}{*}{ ROE } & Correlação de Pearson &, 049 &, 022 & 1,000 &, 067 &,- 035 &,- 026 &,- 005 \\
\cline { 2 - 9 } & Sig. (2 extremidades) &, 702 &, 864 & &, 601 &, 786 &, 841 &, 971 \\
\hline \multirow{2}{*}{ END } & Correlação de Pearson &,$- 260^{*}$ &,$- 685^{* *}$ &, 067 & 1,000 &,$- 619^{* *}$ &,- 225 &,- 227 \\
\hline
\end{tabular}




\begin{tabular}{l|l|r|r|r|r|r|r|r}
\hline & Sig. (2 extremidades) &, 038 &, 000 &, 601 &, 000 &, 074 &, 072 \\
\hline \multirow{2}{*}{ TAM } & Correlação de Pearson &, $567^{* *}$ &, $500^{* *}$ &,- 035 &,$- 619^{* *}$ & 1,000 &, $488^{* *}$ &, $509^{* *}$ \\
\cline { 2 - 8 } & Sig. (2 extremidades) &, 000 &, 000 &, 786 &, 000 & &, 000 &, 000 \\
\hline \multirow{2}{*}{ DN1 } & Correlação de Pearson &, $514^{* *}$ &, $347^{* *}$ &,- 026 &,- 225 &, $488^{* *}$ & 1,000 &, $994^{* *}$ \\
\cline { 2 - 8 } & Sig. (2 extremidades) &, 000 &, 005 &, 841 &, 074 &, 000 &, 000 \\
\hline \multirow{2}{*}{ DN2 } & Correlação de Pearson &, $551^{* *}$ &, $359^{* *}$ &,- 005 &,- 227 &, $509^{* *}$ &, $994^{* *}$ & 1,000 \\
\cline { 2 - 9 } & Sig. (2 extremidades) &, 000 &, 004 &, 971 &, 072 &, 000 &, 000 & \\
\hline
\end{tabular}

Nota. MPG = Média de Pagantes, ROA = Rentabilidade (ROA), ROE = Rentabilidade (ROE), END = Endividamento, TAM = Ln Tamanho, DN1 = Nível de Disclosure N1, DN2 = Nível de Disclosure N2. N = 64. * A correlação é significativa no nível 0,05 (2 extremidades). ${ }^{* *}$ A correlação é significativa no nível 0,01 (2 extremidades).

Fonte: Dados da pesquisa (2017).

Analisando a Tabela 5 e considerando um nível de significância de 1\%, pode-se inferir que há uma correlação positiva entre as variáveis Média de Pagantes e Tamanho de 56,7\%, assim como entre Média de Pagantes e os Níveis de Disclosure N1 e N2 de 51,4\% e 55,1\%, respectivamente. Esses resultados possibilitam concluir que no período analisado, clubes com maior presença de público nos estádios apresentaram também maiores níveis de divulgação contábil. Também pode-se verificar que foram significantes ao nível de $1 \%$ as correlações entre as variáveis Tamanho e os Níveis de Disclosure N1 e N2, corroborando os achados de Holanda et al. (2012) e Benin et al. (2016).

De forma geral, verifica-se existência de proximidade entre as variáveis, conforme identificado na Tabela 5. Nesse sentido, com o objetivo de complementar a avaliação do comportamento entre os indicadores e o nível de disclosure procedeu-se a realização da Análise de Correspondência Múltipla, técnica na qual foram considerados em conjunto os resultados de ambos os anos pesquisados, tendo em vista não ter sido identificada diferença significante entre os disclosures de 2015 e 2016. Para operacionalização do teste as variáveis de desempenho econômico-financeiro, desempenho esportivo e níveis de disclosure, que foram segmentados em quartis cujos intervalos variam entre "Baixo", "Médio Baixo", "Médio Alto" e "Alto", viabilizando a execução da Análise de Correspondência Múltipla. Os intervalos adotados para as variáveis na realização da referida análise estão apresentados na Tabela 6

Tabela 6 - Intervalos adotados para as variáveis (níveis)

\begin{tabular}{l|c|c|c|c}
\hline \multicolumn{1}{c|}{ Variável } & Baixo & Médio Baixo & Médio Alto & Alto \\
\hline Desempenho (ROA) & $<0,076$ & $0,076-0,0025$ & $0,0025-0,0555$ & $>0,0555$ \\
\hline Desempenho (ROE) & $<0,3765$ & $0,075-0,0295$ & $0,0295-0,0965$ & $>0,0965$ \\
\hline Endividamento & $<0,818$ & $0,818-1,1395$ & $1,1395-2,077$ & $>2,077$ \\
\hline Tamanho & $<17,558$ & $17,558-18,609$ & $18,609-19,077$ & $>19,077$ \\
\hline Nível de Disclosure N1 & $<0,438$ & $0,438-0,75$ & $0,625-0,75$ & $>0,75$ \\
\hline Nível de Disclosure N2 & $<0,35$ & $0,35-0,706$ & $0,588-0,706$ & $>0,706$ \\
\hline Média de Pagantes & $<5653$ & $5653-17200$ & $9337-17200$ & $>17200$ \\
\hline Classificação no Campeonato & $<4,25$ & $4,25-12,75$ & $8,5-12,75$ & $>12,75$ \\
\hline
\end{tabular}

Fonte: Dado da pesquisa (2017).

Vale ressaltar que por questões didáticas, a Análise de Correspondência Múltipla foi dividida em duas análises sendo que a primeira delas envolve a relação do desempenho econômico-financeiro em conjunto com o disclosure e também do desempenho operacional associado ao disclosure, já a segunda, investiga a existência de relação específica entre os desempenhos econômico-financeiro e esportivo. Os resultados estão representados nos mapas perceptuais das Figuras 1 e 2.

Figura 1 - Mapas perceptuais do desempenho e disclosure 


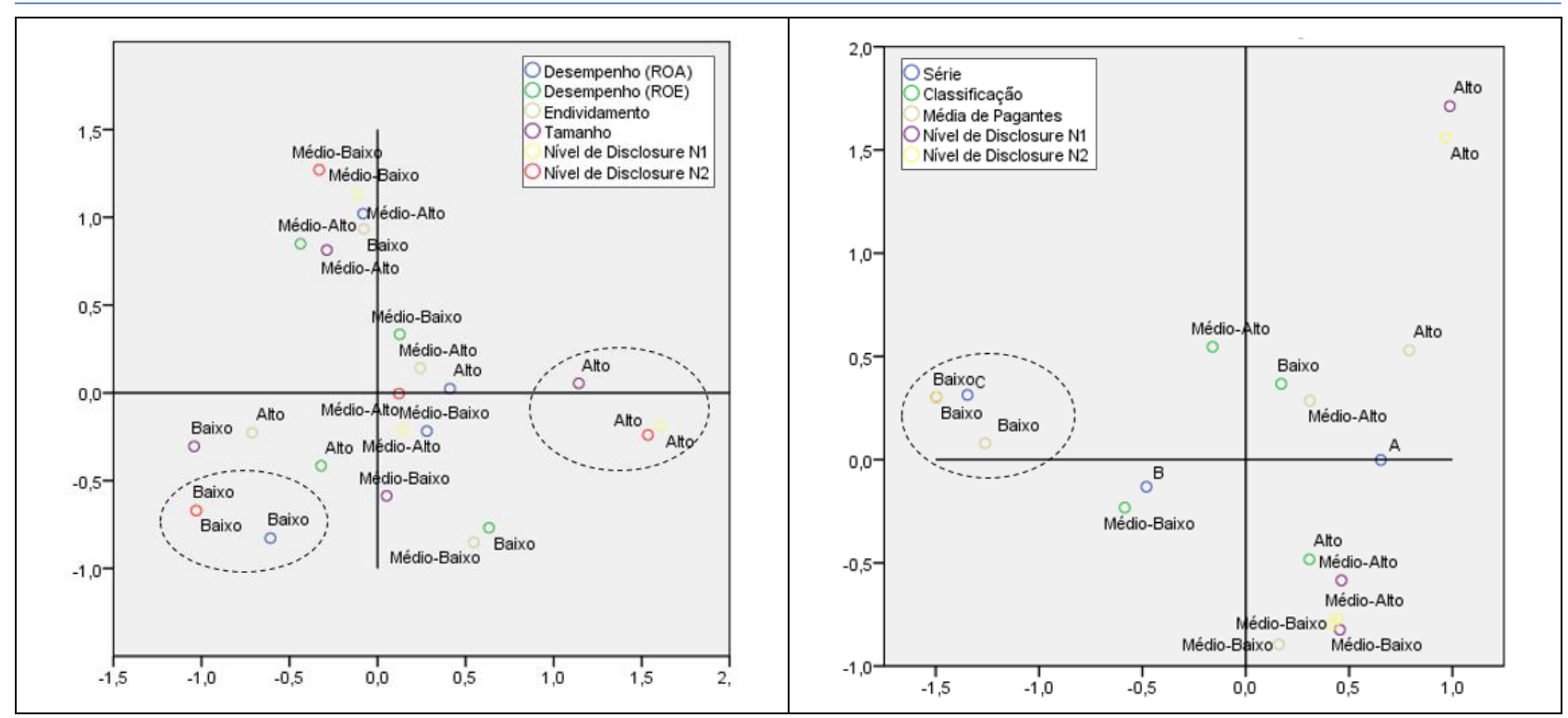

Fonte: Dados da pesquisa (2017).

Observando as associações realizadas e apresentadas através da Figura 1, no que se refere ao desempenho econômico-financeiro e disclosure, pode-se constatar a existência de proximidade entre maior Tamanho e maiores níveis de disclosure, sinalizando a relação entre os maiores clubes de futebol e a maior divulgação de informações. Do mesmo modo, observa-se proximidade entre baixa Rentabilidade (ROA) e menor nível de disclosure, possibilitando inferir que uma menor divulgação de informações pode estar ligada ao baixo desempenho dos clubes estudados. Dessa forma, em sentido geral, percebe-se a associação estatística entre o Desempenho Econômico-Financeiro e os níveis de disclosure corroborando os estudos anteriores (Silva \& Carvalho, 2009; Rezende et al. 2010; Holanda et al., 2012).

Ainda observando a Figura 1, no mapa perceptual referente à associação do desempenho esportivo com o disclosure, não se constata a existência de proximidade entre os níveis de disclosure e o desempenho esportivo dos clubes da amostra. Esse resultado contrapõe os achados de Silva e Carvalho (2009) e de Leite e Pinheiro (2014) que encontraram relação entre o nível de evidenciação contábil e o desempenho esportivo dos clubes estudados. 
Figura 2 - Mapa perceptual do desempenho econômico-financeiro $x$ desempenho esportivo

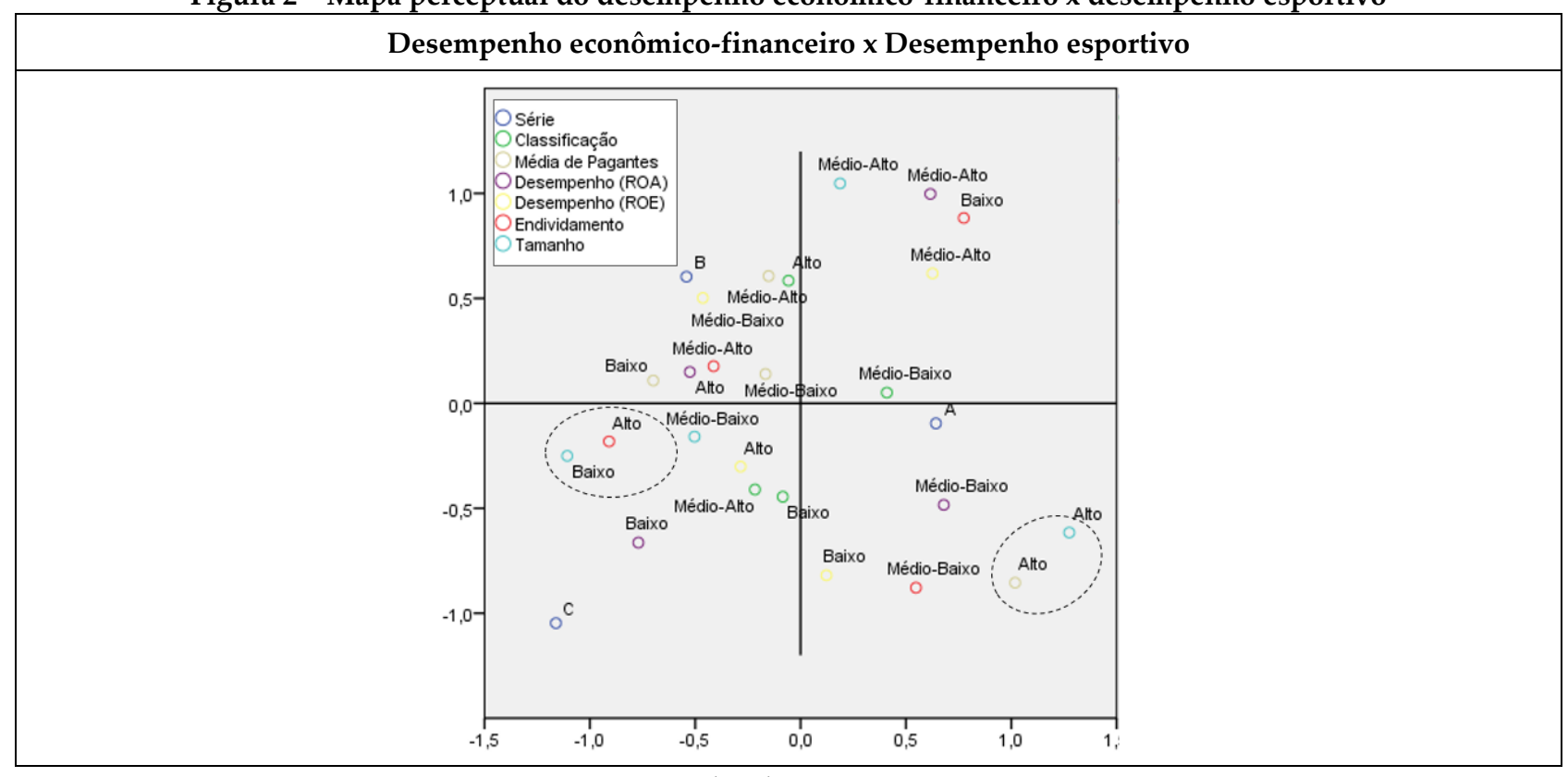

Fonte: Dados da pesquisa (2017).

No tocante à visualização do mapa percentual da Figura 2 é possível verificar proximidade entre maior Tamanho e maior Média de Pagantes o que pode ser explicado pelo fato dos clubes de maior Ativo também possuírem maior número de torcedores. No entanto, de acordo com a análise do mapa, não é possível constatar relação de proximidade entre maior desempenho esportivo (Série e Classificação) e maior desempenho econômico-financeiro (ROA, ROE, Endividamento e Tamanho). Tal resultado contrapõe os achados de Benin et al. (2016) que encontraram associação positiva entre o desempenho esportivo e o tamanho dos clubes por ativo e receita.

Constata-se ainda a relação de proximidade entre alto endividamento dos clubes e baixo tamanho, demonstrando que a adesão ao PROFUT pode ser um incentivo para uma redução do endividamento e, consequentemente, aumento do seu ativo, que neste estudo foi utilizado como proxy para o tamanho. Diante dessa análise, nota-se que os menores clubes brasileiros são aqueles que estão mais endividados, sendo o PROFUT um incentivo ao desenvolvimento dessas entidades.

\section{CONCLUSÃO}

Esta pesquisa teve por objetivo geral investigar o nível de disclosure decorrente da adesão ao PROFUT pelos clubes de futebol brasileiros e sua relação com o desempenho econômico-financeiro e esportivo no decorrer dos anos de 2015 e 2016. Para isso, foram selecionadas 76 demonstrações contábeis de clubes de futebol do Campeonato Brasileiro de 2015 das quais 64 compuseram a amostra final. $\mathrm{O}$ estudo utilizou como técnicas estatísticas teste de diferença entre médias, correlação de Pearson e Análise de Correspondência Múltipla para variáveis representativas do nível de disclosure e dos desempenhos econômico-financeiro e esportivo.

Os resultados obtidos possibilitaram constatar que a adesão ao PROFUT não melhorou o nível de disclosure nos anos de 2015 e 2016, contrapondo assim a expectativa inicial com a entrada em vigor da Lei $n^{\circ} 13.155$ (2015), o que possibilita rejeitar a H2 de que ocorreu aumento no nível de divulgação nos períodos avaliados.

Os achados do estudo permitem identificar que existe relação entre o desempenho econômicofinanceiro e os níveis de disclosure, pois se constatou que clubes com maior tamanho apresentam melhores níveis de disclosure. Em relação ao desempenho esportivo e níveis de disclosure, não se 
constatou relevância estatística que permita comprovar a existência de relação entre as variáveis. No tocante à investigação da relação entre desempenho econômico-financeiro e desempenho esportivo não foi possível constatar associação positiva entre as variáveis. Esses fatos possibilitam a aceitação parcial da $\mathrm{H} 1$ de que há relação entre o disclosure e os desempenhos econômico-financeiro e esportivo, haja vista que se constatou a existência de relação apenas entre o desempenho econômico-financeiro e o disclosure.

Percebe-se que os clubes de futebol não retornam com contrapartidas equivalentes ao refinanciamento das dívidas proporcionadas pelo PROFUT, uma vez que há indícios de que a gestão não consegue retornar nem como melhorias no desempenho econômico-financeiro, nem como desempenho esportivo. Além disso, o mínimo de divulgação de como a assistência governamental é utilizada por esses clubes é devolvido para a sociedade como um todo.

No geral, percebe-se, com os resultados deste trabalho, que os clubes de futebol brasileiros ainda necessitam desenvolver melhores práticas de divulgação contábil a fim de atender os requisitos de divulgação estabelecidos pelas entidades normatizadoras, melhorando a qualidade das informações evidenciadas através de suas demonstrações contábeis.

Por fim, sugere-se para pesquisas futuras um período maior de análise levando em consideração o fato da Lei do PROFUT ser relativamente recente, além da adoção de outras proxies como total de receitas no aspecto econômico-financeiro e análise de desempenho esportivo via ranking da Confederação Brasileira de Futebol.

\section{REFERÊNCIAS}

Bastos, P. S. S., Pereira, R. M., \& Tostes, F. P. (2007). Uma contribuição para a evidenciação do ativo intangível - atletas - dos clubes de futebol. Pensar Contábil, 9(36), 1-16.

BDO RCS Auditores Independentes. (2016). 10ํㅡㅁor das Marcas dos Clubes Brasileiros Recuperado dehttps://www.bdobrazil.com.br/pt-br/publicacoes/publicacoes/10\%C2\%BA-valor-das-marcas-dos-clubes-brasileiros

Benin, M. M., Diehl, C. A., \& Marquezan, L. H. F. (2016, junho). A evidenciação de indicadores não financeiros de medição de desempenho por clubes de futebol brasileiros. Anais do Encontro da Associação Nacional dos Programas de Pós-Graduação em Ciências Contábeis. Ribeirão Preto, SP, Brasil, 10. Recuperado de http://www. anpcont.org.br/congresso.php

Confederação Brasileira de Futebol. (2017). Campeonato Brasileiro de Futebol 2017. Rio de Janeiro. Recuperado de: https://www.cbf.com.br/futebol-brasileiro/competicoes

Coy, D. \& Dixon, K. (2004). The public accountability index: crafting a parametric disclosure index for annual reports. The British Accounting Review, 36(1), 79-106.

Fávero, L. P., Belfiore, P., Silva, F. L., \& Chan, B. L. (2009). Análise de Dados: Modelagem Multivariada para a Tomada de Decisões. ( $4^{\underline{a}}$ ed). Rio de Janeiro: Campus.

Figueiredo, G. H., Santos, V. D., \& Cunha, P. R. (2017). Práticas de evidenciação em entidades desportivas: Um estudo nos clubes de futebol brasileiros. Enfoque Reflexão Contábil, 36(1), 1-21.

Fonteles, I. V. (2013). Assistências governamentais e disclosure socioambiental. (Dissertação de mestrado). Faculdade de Economia, Administração, Atuária e Contabilidade - Universidade Federal do Ceará, Fortaleza, CE, Brasil.

Freund, J. E, \& Simon, G. A. (2000). Estatística aplicada. (9a ed). Porto Alegre: Bookman. 
Fundação Instituto de Pesquisas Contábeis, Atuariais e Financeiras. (2010). Manual de contabilidade societária: aplicável a todas as empresas de acordo com as normas internacionais e do CPC. (3a ed). São Paulo: Atlas.

Galvão, N. S., \& Miranda, L. C. (2016). Participação e evidenciação de atletas nos demonstrativos contábeis de clubes de futebol brasileiro. Revista de Gestão, Finanças e Contabilidade, 6(1), 112-131.

Holanda, A. P., Meneses, A. F., Mapurunga, P. V. R., De Luca, M. M. M., \& Coelho, A. C. D. (2012). Determinantes do Nível de Disclosure em Clubes Brasileiros de Futebol. Revista de Contabilidade do Mestrado em Ciências Contábeis da UERJ, 17(1), 2-17.

Holanda, S. S. P. (2015). Investigação da relação entre disclosure, materialidade e origem legal dos países: um estudo de transações com partes relacionadas (Dissertação de mestrado). Faculdade de Economia, Administração, Atuária e Contabilidade - Universidade Federal do Ceará, Fortaleza, CE, Brasil.

Lei n. 10.672, de 15 de maio de 2003. Altera dispositivos da Lei no 9.615, de 24 de março de 1998, e dá outras providências. Recuperado de http://www.planalto.gov.br/ccivil _03/leis/2003/L10.672.htm

Lei n. 11.638, de 28 de dezembro de 2007. Altera e revoga dispositivos da Lei no 6.404, de 15 de dezembro de 1976, e da Lei no 6.385, de 7 de dezembro de 1976, e estende às sociedades de grande porte disposições relativas à elaboração e divulgação de demonstrações financeiras. Recuperado de http://www.planalto.gov.br/ccivil_03/_ato2007-2010/2007/lei/111638.htm

Lei $n$. 13.155, de 04 de agosto de 2015. Estabelece princípios e práticas de responsabilidade fiscal e financeira e de gestão transparente e democrática para entidades desportivas profissionais de futebol. Recuperado de http://www.planalto.gov.br/ccivil_03/_ato2015-2018/2015 /lei/L13155.htm.

Lei n. 13.262, de 22 de março de 2016. Reabre o prazo previsto no art. 9o da Lei no 13.155, de 4 de agosto de 2015. Recuperado de http://www.planalto.gov.br/ccivil_03/_ato20152018/2016/lei/L13262.htm>.

Lei n. 6.404, de 15 de dezembro de 1976. Dispõe sobre as Sociedades por Ações. Recuperado de http://www.planalto.gov.br/ccivil_03/leis/L6404consol.htm

Lei n. 8.672, de 06 de julho de 1993. Institui normas gerais sobre desportos e dá outras providências. Recuperado de http://legis.senado.gov.br/legislacao/ListaPublicacoes. action?id=137919\&tipoDocumento=LEI\&tipoTexto=PUB

Lei n. 9.615, de 24 de março de 1998. Institui normas gerais sobre desportos e dá outras providências. Recuperado de http://legis.senado.gov.br/legislacao/ListaPublicacoes.actio n?id=148635 \&tipo Documento $=$ LEI\&tipoTexto $=$ PUB

Lei n. 9.940, de 21 de dezembro de 1999. Altera dispositivo da Lei n. 9615, de 24 de março de 1998, que institui normas gerais sobre desporto e dá outras providências. Recuperado de http: //www2.camara.leg.br/legin/fed/lei/1999/lei-9940-21-dezembro-1999-370074-public acaoor iginal-1-pl.html

Lei n. 9.981, de 14 de julho de 2000. Altera dispositivos da Lei no 9.615, de 24 de março de 1998, e dá outras providências. Recuperado de http://www.planalto.gov.br/ccivil_03/leis/L 9981. htm

Leite, D. U., \& Pinheiro, L. E. T. (2014). Disclosure de Ativo Intangível: Um Estudo dos Clubes de Futebol Brasileiros. Enfoque Reflexão Contábil, 33(1), 89-104. 
Loureiro, D. Q., Gallon, A. V., \& De Luca, M. M. M. (2011). Subvenções e Assistências Governamentais (SAG): Evidenciação e Rentabilidade das Maiores Empresas Brasileiras. Revista de Contabilidade e Organizações, 5(13), 34-54.

Maçambanni, M. V., Souza, M. M., Souza, F. C., \& Murcia, F. D. (2012). Relação entre o nível de disclosure do capital intelectual e características das companhias listadas no índice BM\&FBOVESPA. Revista Alcance, 19(3), 345-361.

Maia, A. B. G. R., \& Vasconcelos, A. C. (2016). Disclosure de Ativos Intangíveis de Clubes de Futebol Brasileiros e Europeus. Revista Contabilidade Vista e Revista, 27(3), 1-31.

Maia, A. B. G. R., Cardoso, V. I. C., \& Ponte, V. M. R. (2013). Práticas de disclosure do ativo intangível em clubes de futebol. Revista de Administração, Contabilidade e Economia da FUNDACE, 4(1), 1-17.

Mapurunga, P. V. R., Morais, C. R. F., Ponte, V. M. R., Rebouças, S. M. D. P., \& Carneiro, A. R. A. (2015). Disclosure de informações acerca do pagamento baseado em ações e sua associação com os atributos das firmas. Revista Contabilidade, Gestão e Governança, 18(1), 5-25.

Mota, A. F., Brandão, I. F., \& Ponte, V. M. R. (2016). Disclosure e materialidade: evidências nos ativos intangíveis dos clubes brasileiros de futebol. Revista de Administração, Contabilidade e Economia RACE, 15(2), 175-200.

Murcia, F. D., \& Santos, A. (2010, junho). Teoria do disclosure discricionário: evidências do mercado brasileiro no período 2006-2008. Anais do Encontro da Associação Nacional dos Programas de PósGraduação em Ciências Contábeis. Natal, RN, Brasil, 4. Recuperado de http://www. anpcont.org.br/ congresso.php

Oliveira, J. F. R.,Viana Júnior, D. B. C., Ponte, V. M. R., \& Domingos, S. R. M. Indicadores de desempenho e valor de mercado: uma análise nas empresas listadas na BM\&FBovespa. Revista Ambiente Contábil, 9(2), 240-258.

Polit, D. F., Beck, C. T., \& Hungler, B. P. (2011). Fundamentos de Pesquisa em Enfermagem: métodos, avaliação e utilização. (7a ed). Porto Alegre: Artmed.

Pronunciamento Técnico CPC 07 (R1), de 05 de novembro de 2010. Subvenção e Assistência Governamentais. CPC - Comitê de Pronunciamentos Contábeis. Recuperado de http://static.cpc.mediagroup.com.br/Documentos/167_CPC_07_R1_rev\%2003.pdf

Resolução CFC n. 1.005, de 17 de setembro de 2004. Aprova a NBC T 10.13 - Dos Aspectos Contábeis Específicos em Entidades Desportivas Profissionais. Recuperado de http://www1. cfc.org.br /sisweb/sre/docs/RES_1005.doc

Resolução CFC n. 1429, de 25 de janeiro de 2013. Aprova a ITG 2003 - Entidade Desportiva Profissional. Recuperado de http://www1.cfc.org.br/sisweb/SRE/docs/Res_1429.pdf

Rezende, A. J., \& Dalmácio, F. Z. (2015). Práticas de Governança Corporativa e Indicadores de performance dos Clubes de Futebol: uma Análise das Relações Estruturais. Revista Contabilidade, Gestão e Governança, 18(3), 105-125.

Rezende, A. J., Dalmácio, F. Z., \& Salgado, A. L. (2010). Nível de disclosure das atividades operacionais, econômicas e financeiras dos clubes brasileiros. Revista Contabilidade, Gestão e Governança, 13(2), 36-50.

Rodrigues, R, N., Silva, G. C., \& Faustino, O. W. C. (2011) Subvenção e assistência governamental sob a ótica do CPC 07: reconhecimento contábil após a Lei 11.638/2007 nas entidades privadas no estado de Pernambuco. Registro Contábil - Recont, 2(3), 35-45. 
Roesch, S. M. A. (2005). Projetos de estágio e pesquisa em administração: guia para estágios, trabalhos de conclusão, dissertações e estudos de casos. ( $3^{\mathrm{a}}$ ed). São Paulo: Atlas.

Salotti, B. M., \& Yamamoto, M. M. (2008). Divulgação voluntária da demonstração dos fluxos de caixa no mercado de capitais brasileiro. Revista Contabilidade e Finanças - USP, 19(48), 37-49.

Santos, E. S., \& Calixto, L. (2010) Impactos do início da harmonização contábil internacional (Lei 11.368/07) nos resultados das empresas abertas. RAE - Eletrônica, 9(1), 1-26.

Silva, C. A. T., Teixeira, H. M., \& Niyama, J. K. (2009, julho). Evidenciação contábil em entidades desportivas: uma análise dos clubes de futebol brasileiros. Anais do Congresso USP de Controladoria e Contabilidade. São Paulo, SP, Brasil, 9. Recuperado de http://www.congressousp.fipecafi.org/anais/artigos92009/305.pdf

Silva, J. A. F, \& Carvalho, F. A. A. (2009). Evidenciação e desempenho em organizações desportivas: um estudo empírico sobre clubes de futebol. Revista de Contabilidade e Organizações, 3(6), 96-116.

Silva, L. M. [Lucas], \& Silva, L. M. [Leonardo]. (2016). Futebol-empresa: Análise da Lei de Responsabilidade Fiscal do Futebol Brasileiro. Revista Eletrônica Direito e Política, 11(2), 508-533.

Souza, A. G., Sousa, W. D., Nascimento, J. C. H. B., \& Bernardes, J. R. (2016). Disclosure em demonstrações financeiras: um estudo sobre o nível de evidenciação contábil de clubes de futebol brasileiros no ano de 2013. PODIUM Sport, Leisure and Tourism Review, 5(3), 1-19.

Taveira, J. H. P. S. (2009). Conformidade do Disclosure das Subvenções Governamentais nas Empresas de Capital Aberto (Dissertação de mestrado). Programa de Pós-Graduação e Pesquisa em Administração e Economia, Faculdade de Economia e Finanças IBMEC, Rio de Janeiro, RJ, Brasil. 